\title{
Comunidad obrera, género y politicas asistenciales: \\ Comodoro Rivadavia, 1922-1932
}

\author{
Andrea Andújar \\ CONICET/IIEGE-UBA/UNPSJB
}

\section{Introducción}

El 5 de noviembre de 1926 Carmen Fernández, una española que rondaba los 30 años de edad, comenzó a trabajar como encargada de uno de los baños públicos construidos por la empresa Yacimientos Petroliferos Fiscales (YPF) en su campamento de Comodoro Rivadavia. $\mathrm{El}$ jornal diario que percibía por mantener limpio el lugar y atenderlo cotidianamente era de $\$ 3,50$, dos pesos menos que lo ganado por un obrero petrolero no calificado. Aunque no era demasiado, ese dinero la ayudaba para mantenerse a sí misma y a su pequeño hijo pues constituía el único ingreso con el que contaba desde la muerte de su marido, Julio Montoya, un trabajador petrolero con quien habia vivido en una de las moradas construidas y destinadas por la empresa para los obreros que tenían familia. Si lograba conservar su nuevo empleo, no se vería obligada a abandonar la vivienda. Pero además, tendría la oportunidad de que su hijo, cuando alcanzara la edad suficiente, pudiera asistir a la Escuela $n^{\circ} 2$, edificada por la empresa para brindar educación primaria a los niños y niñas de las familias proletarias.

Situaciones como las de Carmen no constituyeron una rareza en esos tiempos. Era usual que YPF empleara a mujeres que como ella habian enviudado y tenían hijos e hijas, para atender los baños públicos para mujeres y para varones con duchas de agua fria y caliente montados en los barrios obreros del yacimiento. Otras podian desempeñarse como sirvientas en las casas del personal jerárquico o como enfermeras y parteras del hospital Alvear, construido por la petrolera estatal e inaugurado en 1924. Tal fue el caso de Josefa Ezcurra de Ciafardini, otra española llegada de Buenos Aires que consiguió trabajo en dicho hospital en abril de 1928 bajo condiciones mejores que las de Carmen. 
Josefa no sólo estaba mensualizada sino que cobraba $\$ 200$ por mes, casi el doble de lo que percibía la encargada del baño. Otras, como la húngara Bárbara Danesa, eran contratadas para ocuparse de la limpieza de oficinas administrativas o las gamelas, comedores colectivos para los trabajadores. ${ }^{1}$

Esta breve reseña sobre cómo ciertas mujeres se ganaban la vida en el campamento de la compañia estatal permite divisar algunas de las medidas asistenciales desplegadas por la gerencia empresarial en favor de los obreros y sus familias. Asimismo, posibilita interrogar de qué manera esa política de beneficios que comprendía la construcción de viviendas y baños públicos, la atención de la educación elemental o de la salud para niños y niñas, que se sostuvo parcialmente en el trabajo de las mujeres, apeló a ciertas nociones de masculinidad y feminidad que reproducian, tanto por el tipo de labor como por el salario ganado, una división jerárquica entre las trabajadoras y los trabajadores petroleros.

En la actualidad, existen diversos estudios que se han preocupado por reconstruir esta política asistencial deteniéndose en el diseño, contenido y los propósitos que le imprimiera quien fuera considerado uno de sus principales impulsores, el coronel Enrique Mosconi. Al examinar su puesta en práctica entre los años 1922 y 1930, período en el que este ingeniero militar estuvo al frente de la Dirección General de la compañia, tales trabajos advirtieron la multiplicidad de aspectos de la vida cotidiana laboral y social abarcadas por estas medidas asistenciales (Cabral Marques, 2011, 2013; Cabral Marques y Crespo, 2006; Márquez, 1995; H. Palermo, 2012). En vínculo con ello, indagaron la incidencia de esta política asistencial en la edificación de la comunidad laboral petrolera y, de tal modo, en la modelación de las percepciones y sentidos compartidos entre las trabajadoras y los trabajadores que la habitaban, en la cultura y en la identidad proletaria. Ciertos trabajos se interesaron además por explorar las nociones de género que permearon el desarrollo de esta actividad extractiva y cómo las mismas delinearon roles diferenciados y jerárquicos entre mujeres y varones (Ciselli, 2001, 2002; Crespo, 2005; H. Palermo, 2014). Algunos recurrieron a diversas nociones conceptuales para interpretar los orígenes y alcances de esta política de beneficios. Así, su decurso bajo el liderazgo de Mosconi fue interpretado como un modelo de profundo disciplinamiento social, pedagogía de la dominación o hegemonía empresaria, calibrándose sus logros a partir de cuestiones tales como la progresiva desactivación de huelgas y organizaciones sindicales mientras este coronel estuvo al

1. La reconstrucción de las labores de estas mujeres se basó en los datos proporcionados por las fichas de personal de YPF. Fichas del personal de YPF, archivo personal de Susana Torres. Agradezco a la historiadora Viviana Bórquez la posibilidad de acceder a este acervo documental. 
frente de la petrolera estatal, la aceptación de unas nociones de género que obraban en pos de la inferiorización de las mujeres, la conversión del campamento de YPF en una "institución total" y la gestación de una identidad de clase que posteriormente cristalizaria en una particular manera de autopercibirse y denominarse: ser un "ypefeano", esto es, parte de una comunidad cuyos intereses se amalgamaban bajo definición de la empresa (Cabral Marques, 2013; Capogrossi, 2014; Ciselli, 2001; Márquez, 1995; H. Palermo, 2012).

Estas investigaciones, al enfocarse en la reconstrucción de esta política asistencial examinando las diversas instancias vitales que atendía y las finalidades profesadas por su principal cultor, generaron un conocimiento más profuso de la historia del mundo del trabajo petrolero de YPF en las primeras décadas del siglo XX. Sin embargo, el énfasis otorgado al afán disciplinador de la dirigencia empresarial y, consecuentemente, a su capacidad de controlar y moldear todos los aspectos de la vida laboral y social y de la identidad y la cultura proletarias, dificulta dimensionar la participación activa de los trabajadores en la gestación de esas medidas. Es para explorar tal intervención que este trabajo, acercamiento preliminar fruto de una investigación en progreso, vuelve sobre esa política asistencial situándose en su implementación en el yacimiento de YPF de Comodoro Rivadavia durante los años 1922 y 1932. Específicamente, busca reconocer cómo en el trazado de esa politica de beneficios, en sus limites y alcances, incidieron demandas por derechos labradas por esos trabajadores y trabajadoras en base a sus propias expectativas y maneras de experimentar las condiciones de explotación, en lo que consideraron justo para sus vidas y en las negociaciones y confrontaciones que visible o solapadamente libraron contra sus patrones para hacerlos valer. Al interrogarse por esa experiencia histórica, este análisis se propone en definitiva resituar tales medidas como parte de un proceso dinámico y conflictivo que, enmarcado bajo específicas relaciones de dominación, habría tenido tanto de tensiones y negociaciones como de abiertos y velados enfrentamientos de clase.

A su vez, tal punto de mira invita a reflexionar sobre la arquitectura de la comunidad laboral en cuya trama se forjó esa política pues el protagonismo asignado a la dirigencia empresarial en su formulación también ha resultado en concluir que dicha comunidad fue moldeada a imagen y semejanza del diagrama de la gerencia de YPF. Nuevamente entonces, la agencia de trabajadores y trabajadoras, los sentidos que construyeron y asignaron a ese lugar donde ganaron su sustento, habitaron, se casaron, criaron a sus hijos e hijas, batallaron y negociaron quedan o bien desdibujados o bien estabilizados como reflejo de las voluntades patronales.

Inscripto en la perspectiva de la historia social y los estudios de 
género, y elaborado en base a la revisión de un acervo documental compuesto por circulares y notas de la empresa petrolera, informes de funcionarios del Estado nacional, registros de la comisaría que funcionaba dentro del campamento central de YPF, la prensa local, periódicos de organizaciones de izquierda y de sindicatos que intervinieron en ese escenario, entre otras fuentes, este trabajo despliega su propuesta en dos apartados. El primero se enfoca en la historia del yacimiento estatal desde sus inicios hasta la creación de YPF. El segundo se interna en la política asistencial de la empresa bajo el liderazgo de Enrique Mosconi, indexando a su análisis interrogantes relativos a la construcción de la comunidad laboral petrolera.

\section{Avatares de los primeros años del yacimiento estatal}

Tanto la fundación de YPF como la formación de una comunidad petrolera aledaña a sus yacimientos fue parte de un proceso gradual y complejo, atravesado por variadas dificultades. Su origen se remonta a diciembre de 1907, con el hallazgo del primer pozo petrolero de la Argentina en Comodoro Rivadavia. El hecho de que su localización estuviera en tierras fiscales y que las mismas integraran el Territorio Nacional de Chubut proporcionó al Estado nacional la oportunidad de participar activamente en la actividad extractiva. Fue en ese marco como dispuso en 1910 la creación de la Dirección General de Explotación de Petróleo de Comodoro Rivadavia (DGEP), organismo dependiente del Ministerio de Agricultura de la Nación y encargado de organizar la explotación del yacimiento, su administración y la regulación de las relaciones laborales en su interior.

Sin embargo, las divergentes visiones entre los sectores políticos dirigentes sobre la conveniencia de la intervención estatal en la extracción de petróleo y la cantidad de recursos que debían destinarse a la actividad obstaculizaron inicialmente la expansión sostenida de la explotación fiscal. Esas discrepancias giraban en parte en torno a la trascendencia de este combustible para el funcionamiento de una economía que, sustentada en la exportación de productos primarios agrícolas y ganaderos para consumo del mercado británico, tenía en el carbón su fuerza motriz preponderante. Aunque importado desde los yacimientos carboníferos del sur de Gales, su bajo costo colaboraba en mermar el interés por contar con una fuente alternativa de energía. De hecho, para 1913, en vísperas de la Primera Guerra Mundial, el petróleo constituía tan sólo el $5 \%$ del combustible utilizado en la Argentina (Solberg, 1986). Fue justamente el devenir del conflicto bélico el que abonó una perspectiva más favorable entre los círculos dirigentes sobre las potenciales ventajas de la producción estatal de petróleo. De todos modos, hasta los primeros 
años de la posguerra, el respaldo financiero brindado por el gobierno nacional a la explotación patagónica fue exiguo, motivo por el cual la DGEP de Comodoro Rivadavia se mantuvo con un escaso presupuesto, solventándose centralmente con las utilidades de la venta de combustible a los ferrocarriles estatales y la Marina (Solberg, 1986).

Otro obstáculo decisivo para el desarrollo del yacimiento estatal radicaba en la escasez de mano de obra. La baja densidad poblacional de la región dificultaba inicialmente el hallazgo de suficientes brazos dispuestos a establecerse en las inmediaciones del yacimiento. ${ }^{2}$ Tampoco resultaban un incentivo los salarios ofrecidos. Para 1917, por ejemplo, el dinero obtenido mensualmente por un obrero petrolero no calificado a cambio de 12 horas diarias de trabajo de lunes a sábado y 6 horas los domingos, oscilaba entre $\$ 80$ y $\$ 100$ mensuales. El alquiler de una habitación en la pequeña ciudad de Comodoro Rivadavia, situada a $3 \mathrm{~km}$ al sur del yacimiento, consumía el $10 \%$ de lo ganado, a lo cual se agregaba el gasto en alimentos -cuyos precios eran onerosos pues buena parte de lo que se consumía llegaba en buque desde Buenos Aires, situada a alrededor de $1.800 \mathrm{~km}$ de distancia-, en agua -también encarecida por su escasez- y en vestimenta. ${ }^{3}$ Por su parte, si el trabajador optaba por vivir dentro de los confines del yacimiento y evitar así recorrer diariamente de ida y de vuelta la distancia que separaba la ciudad del lugar de trabajo, las penurias no eran menores. Carpas de lona o galpones con piso de tierra, paredes de madera y techos de zinc divididos en pequeñas habitaciones donde se alojaban no menos de cuatro personas eran los tipos de albergue habitualmente existentes (Ezpeleta, 1957). El hacinamiento, la falta de higiene, de calefacción y de agua potable primaban en las condiciones de vida en una región que ofrecía pocos alicientes para habitar en ella, además, con sus severos inviernos, la falta de vegetación y de fuentes de agua dulce. A su vez, el costo de los artículos de primera necesidad era aún más gravoso que en el pueblo, dados los sobreprecios que cobraban los proveedores particulares habi-

2. Para 1914, la población del Territorio Nacional del Chubut arribaba a 23.065 personas -14.522 varones y 8.543 mujeres- (Tercer Censo Nacional de Población, junio de 1914, p. 180). Según otros cálculos, hacia 1917 la región de Comodoro Rivadavia contaba con 3.232 habitantes, de los cuales 1.562 residian en el yacimiento fiscal (Armesto, Córdoba y Figueroa, 2001).

3. Algunos datos sobre precios permiten advertir la carestía del costo de vida en ese entonces en la localidad patagónica. Para 1916, por ejemplo, en Comodoro Rivadavia $1 / 2 \mathrm{~kg}$. de azúcar costaba $\$ 1,50$ y 1 docena de huevos $\$ 3$, mientras que en Buenos Aires rondaban $\$ 0,60$ y $\$ 0,59$ respectivamente. El salario promedio de un trabajador no calificado, por su parte, en la ciudad capital del país alcanzaba los $\$ 78$ mensuales en tanto que en Comodoro Rivadavia no superaba los $\$ 100$. Ver Boletín del Departamento Nacional del Trabajo (BDNT) n ${ }^{\circ} 36$, enero de 1918 y BDNT Anuario Estadístico 1917, n 42, marzo de 1919; Solberg, 1986: 68; Armesto, Córdoba y Figueroa, 2001. 
litados para vender sus mercaderías dentro del campamento. También la atención de la salud, que revestía suma importancia tanto por las condiciones climáticas como por los riesgos de accidentes de trabajo, era deficitaria pues solo se podía recurrir a una pequeña enfermería ubicada a $2 \mathrm{~km}$. de distancia del yacimiento, con capacidad para cuatro camas y una carreta tirada por caballos para trasladar a enfermos y accidentados (Ezpeleta, 1957).

A pesar de todo, el campamento fue experimentando un paulatino crecimiento. De unas pocas decenas de varones que trabajaban y vivian alli hacia 1911, seis años más tarde contaba con 1.400 obreros y empleados. Alrededor del $80 \%$ era de origen europeo, primando entre ellos españoles, portugueses, búlgaros e italianos, seguidos por alemanes, rusos, austriacos, griegos y rumanos, en su mayoria solteros (Castiñeira Castro y García, 1999). Si bien esta preponderancia de población extranjera no era extraña en un país que desde 1880 hasta 1914 había recibido a millones de inmigrantes del viejo continente, las razones del incremento poblacional del yacimiento habrian estado ligadas a la crisis económica desatada con la Primera Guerra Mundial, y específicamente, a sus efectos negativos sobre el nivel de empleo industrial fundamentalmente en los dos centros urbanos más importantes en esos momentos, la ciudad de Buenos Aires y la de Rosario. ${ }^{4}$ Como ya se ha señalado (Cabral Marques y Crespo, 2006), el intento de probar suerte en ese sur lejano, estimulado por informaciones de familiares y amigos residentes alli sobre las posibilidades de hallar trabajo en un ámbito en el que además ciertas habilidades en el manejo de maquinarias o en la construcción podían ser valoradas, habria alentando a muchos trabajadores a migrar en dirección a Comodoro Rivadavia y, si todo salía bien, llevar luego a sus familias.

De todos modos, la distancia entre las expectativas y la realidad de las condiciones de vida y laborales en el yacimiento petrolero, sumado a la posible experiencia que en términos de organización y acción colectiva muchos de esos obreros podian portar, ayudaron al estallido de una huelga durante el segundo semestre de 1917. Iniciado el 29 de septiembre, el conflicto involucró a "945 obreros de los 1.054 que revistan como tales" ${ }^{\prime}$ y se sostuvo durante un mes y medio. En los mitines y manifestaciones por las calles de la ciudad organizadas para publicitar el conflicto y sumar adherentes entre los trabajadores del pueblo, podian escucharse cánticos como el que sigue:

4. Acorde con un censo realizado para Capital Federal, el 7,5\% de los 312.997 trabajadores ocupados en agosto de 1915 había perdido su empleo para agosto del año siguiente (BDNT, $\mathrm{n}^{\circ} 36$, enero de 1918).

5. $B D N T, \mathrm{n}^{\circ} 42$, marzo de 1919, pág. 213. 
Reclamamos ocho horas / Y el aumento de jornal / Ay, ay, ay! / Y el aumento de jornal. / El señor cura del pueblo / ha entendido la razón / y el que no la ha comprendido / es el burro de Sol / Ay, ay, ay! / Es el burro de Sol. (Citado por Torres, 1995)

A las exigencias de la reducción de la jornada laboral y el incremento de los jornales explicitadas en el estribillo, se agregaba el reclamo de un "trato con mayor respeto" por parte de la dirigencia empresarial, ${ }^{6}$ representada fundamentalmente por el ingeniero Leopoldo Sol, máxima autoridad de la Comisión Administradora de la DGEP de Comodoro Rivadavia y a quien se aludía en la canción. El paro fue levantado el 14 de noviembre, luego de que el gobierno nacional, a pesar de las objeciones elevadas por Sol, fallara a favor de la mayoría de las demandas obreras. Así, se obtuvo un $20 \%$ de aumento en jornales inferiores a $\$ 4$ diarios, $10 \%$ para los que superaran tal monto, $30 \%$ de bonificaciones por horas extraordinarias, el reconocimiento de las 8 horas de trabajo y la promesa de mejora de las viviendas y de la creación de una cooperativa de consumo para abaratar los costos de alimentos y vestimenta. ${ }^{7}$ Mas los resultados del conflicto excedieron la satisfacción de los reclamos de los trabajadores. Por un lado, se produjo un recambio en la gerencia del yacimiento que comprendió su parcial militarización. Ante la renuncia de Sol motivada por el adverso resultado del conflicto a sus pretensiones, el Poder Ejecutivo nacional nombró a Enrique Fliess, un capitán del Ejército enviado desde Buenos Aires al mando de 150 marinos para intervenir en el curso de la protesta. A partir de entonces, la dirigencia empresarial contaria entre sus integrantes con oficiales reclutados entre las Fuerzas Armadas. Posiblemente en esa resolución gubernamental gravitara la mayor importancia estratégica que algunos integrantes de la clase dirigente comenzaban a otorgar a la explotación del oro negro en ese mundo en guerra (H. Palermo, 2012; Solberg, 1986). Pero también puede suponerse que fue el fruto de un ensayo político orientado a contener a una clase obrera que expresaba sus intereses en una acción colectiva de protesta. El paro había demostrado cómo esos trabajadores, a pesar de sus diversos orígenes nacionales, de las distintas lenguas en las que hablaban, de los variados puestos que ocupaban dentro de la empresa, habían conseguido edificar lazos entre sí y, además, con los de la localidad, pues la huelga había suscitado el apoyo de ciertos trabajadores y comerciantes de la pequeña ciudad. Esos lazos habrian surgido en una cotidianeidad que comprendia tanto el lugar de trabajo

6. La Protesta, 5 de octubre de 1917, y La Prensa, $1^{\circ}$ de noviembre de 1917.

7. BDNT, $\mathrm{n}^{\circ} 42$, marzo de 1919. 
como los bares y prostíbulos del pueblo -pues en el campamento estos últimos estaban prohibidos-, las viviendas del yacimiento y las improvisadas canchas de fútbol en las que jugaba el Club Recreativo de $\mathrm{Km}$. 3 , un equipo formado por los obreros y empleados del yacimiento que el año anterior había disputado su primer encuentro con otro equipo de la ciudad (Carrizo, 2006). Esos vínculos tejidos en tales espacios habrian colaborado en el intercambio de opiniones sobre la vida y el trabajo, sobre qué hacer frente a ello, cuándo y cómo; en definitiva, habría sido a través de ellos como se planificó y decidió la huelga.

Asimismo, esa experiencia compartida y condensada en el conflicto motivó una segunda deriva del mismo: la formación de la Federación Obrera Petrolifera (FOP). Creada a fines de noviembre de 1917, esta organización sindical de corte anarco-sindicalista, organizada en seccionales fiscalizadas por un Comité Central, editaba El Obrero Petrolífero, un periódico dedicado a la difusión de su ideario así como de aquellas cuestiones relativas a los problemas y la organización obrera petrolera local. ${ }^{8}$ Ello abonó el crecimiento de la FOP que, desde entonces, dinamizó distintas confrontaciones con la empresa, con resultados dispares no por la cantidad de obreros involucrados sino en materia de reivindicaciones obtenidas. En varias ocasiones, como en el caso de los conflictos de noviembre y diciembre de 1918, o los subsiguientes de agosto y diciembre de 1919 en reclamo de cuestiones tales como mejoras salariales, la reducción de la jornada laboral a 8 horas -reivindicación que solo había sido satisfecha formalmente luego del paro de 1917- o la mejoria de las condiciones habitacionales y de higiene en el campamento, la respuesta de la dirigencia estatal fue la represión. Así, se acudió al ejercicio de la fuerza mediante el uso de batallones del Ejército traídos desde Buenos Aires, a la expulsión de los considerados "agitadores" a través de la aplicación de la Ley de Residencia o la conformación de "listas negras" que eran compartidas con las gerencias de las restantes firmas petroleras para evitar la contratación de aquellos sospechados de ser anarquistas o bolcheviques. Esta política se reforzaba además con los intentos por controlar la vida de los obreros mediante el espionaje de apuntadores, personal contratado por la empresa y habilitado a irrumpir en el trabajo y en las viviendas por sorpresa. Empero, también se acudió a la implementación de un conjunto de medidas destinadas a satisfacer ciertas demandas y modificar algunas condiciones de la vida cotidiana que generaban el descontento. Si bien algunas de ellas comenzaron a ponerse en práctica bajo la administración de Fliess,

8. Debe señalarse que a comienzos de noviembre de ese año y también como resultado de la huelga se fundó otra organización sindical, la Sociedad de Jefes de Sondeo y Aspirantes, que reunía mayoritariamente a trabajadores austríacos y alemanes (Torres, 1995). 
su ejecutor protagónico sería Enrique Mosconi, un militar vinculado con el partido gobernante desde 1916, la Unión Cívica Radical (UCR), y nombrado Director General de YPF en octubre de 1922, la empresa estatal creada en junio de ese año por decreto presidencial en base a la reorganización de la DGEP de Comodoro Rivadavia.

\section{Entre el obrero soñado por el patrón y la pesadilla proletaria: vida, conflicto $y$ asistencia en YPF}

En el inicio del cuarto capítulo de su libro Obras, escrito seis años más tarde de su alejamiento de la conducción de YPF, el coronel Enrique Mosconi aseveraba:

Al encarar la organización del personal del YPF lo hicimos con criterio humano, social y práctico, en bien de los intereses generales y del progreso de la Nación. Nos proponíamos formar, y esto se logró, un personal de hombres fuertes, sanos de cuerpo y espíritu (...) La Dirección General se proponía velar y subvenir en la forma más completa posible al bienestar general del personal de la organización, en forma tal que el jefe de familia no sintiera disminuidas su energía y su capacidad de trabajo por preocupaciones inherentes a las necesidades del hogar. En cambio, exigimos del personal, conducido con estricta equidad y justicia, una disciplina inflexible y una rigidez absoluta en el cumplimiento de deberes y obligaciones (Mosconi, 1984: 71).

Estas afirmaciones prologaban la reseña de las medidas asistenciales puestas en práctica bajo su gestión en pos de los trabajadores petroleros y sus familias. Entre ellas se contaban bonificaciones extra-salariales (como asignaciones familiares por paternidad y por maternidad, bonos por antigüedad, gratificaciones anuales extraordinarias o premios a la puntualidad), la provisión de viviendas (cuya disposición espacial y dimensiones respondian tanto al estado civil de los trabajadores y la composición numérica de la familia como a las jerarquías laborales), la atención de la salud (mediante la provisión de servicio médico gratuito a domicilio, la inauguración del Hospital Alvear y descuentos en medicamentos), la educación formal y la capacitación de los obreros (a través de la construcción de escuelas con ciclo elemental para los hijos y las hijas de las familias proletarias, de una escuela nocturna para adultos analfabetos y semi-analfabetos, y la firma de un acuerdo con la congregación salesiana para la construcción de una escuela orientada a brindar estudios de especialización técnica exclusivamente para los 
varones que concluyeran el ciclo elemental), la instalación de comedores con precios módicos para obreros y empleados, y de baños públicos en los barrios del campamento (Mosconi, 1984).

La puesta en práctica de estos beneficios, con su pretensión de liberar al "jefe de familia" de las inquietudes de la subsistencia del hogar, apostaba no sólo a fomentar el incremento de la capacidad de trabajo del obrero petrolero sino también de su lealtad hacia la empresa. A tales fines se sumaba el impulso de variadas actividades recreativas. Algunas comprendian la organización de orquestas y veladas musicales, de bailes y reuniones para caridad, y de campeonatos deportivos de fútbol o de básquet -prácticas que retomaban en parte usos del tiempo de ocio realizados por los trabajadores con antelación-. Otras remitian al festejo conmemorativo de ciertos hitos del proceso independentista mediante la realización de desfiles militares acompañados por actos organizados por las escuelas de niños y niñas del campamento. Tales festividades concitaban especial empeño por parte de la gerencia de la empresa pues eran la ocasión para estimular la circulación y adhesión a valores vinculados con la defensa de la Nación y su soberania, sobre todo en materia de sus recursos hidrocarburíferos. A su vez, Mosconi reforzaba tal convicción nacionalista, explicitada en sus controversias sobre la participación extranjera en la explotación del petróleo local, ${ }^{9}$ con otras iniciativas dirigidas hacia la clase trabajadora de la petrolera estatal. Específicamente, hacia aquella expresión política que ponía en tela de juicio la existencia de la nación y del propio sistema burgués. En ese sentido, la pretensión de promover la unicidad de intereses de obreros, empleados y patrones tras el nacionalismo petrolero se enlazaba con el de poner término a una conflictividad laboral que portaba el signo del anarquismo. Fue así como se prohibió toda actividad sindical ampliando la práctica de la confección de listas negras y la expulsión de los "agitadores" fundamentalmente a partir del intento de la FOP de convocar a una huelga hacia fines de 1922. Pero como esta adscripción político-ideológica era anexada al origen europeo de la mayoría de los trabajadores, Mosconi procuró enfrentarla acudiendo también a la "argentinización" de la mano de obra, es decir, al reemplazo de los obreros extranjeros mediante la contratación de trabajadores provenientes de áreas rurales de las provincias del norte argentino -sobre todo Catamarca-, vistos como más dóciles en base a una supuesta ausencia de experiencia fabril y sindical (Mosconi, 1984).

Por otra parte, esta política asistencial descansaba en nociones de

9. En referencia a las confrontaciones de Mosconi con las empresas extranjeras -fundamentalmente con la firma Standard Oil de New Jersey- y sus ecos en las políticas del gobierno de la UCR, véase Solberg (1986) y Gadano (2006). 
masculinidad y feminidad obreras que, si bien no eran exclusivamente profesadas por la dirigencia de YPF, reforzaban una división sexual del trabajo que ponderaba de manera desigual a varones y mujeres. ${ }^{10} \mathrm{De}$ tal modo, los primeros eran preconizados como proveedores del hogar proletario; pero además, como seres idóneos para cumplir con los requerimientos de fuerza física del trabajo petrolero y depositarios de ciertos valores asociados a ello tales como valentía, cuidado y disciplina, nociones que debían ser inculcadas no sólo en el trabajo sino también a través de la educación y de la práctica de deportes. ${ }^{11}$ En contrapunto, las mujeres eran situadas como responsables del cuidado y la reproducción familiar, educables en labores como la costura y la preparación de alimentos, y subordinadas a los varones en tanto madres y esposas (Crespo, 2005). Esa marca genérica, asimismo, patentaba las tareas remuneradas que la empresa les ofrecía ya que ocuparse de los enfermos en el Hospital, de la enseñanza en la escuela, de la limpieza de los baños públicos, las oficinas y las gamelas eran labores concomitantes a su rol hogareño. Más aún, según un estudio, la contratación de las viudas habria buscado mantenerlas radicadas en el campamento a fin de garantizar que sus hijos se volvieran obreros petroleros una vez alcanzada la edad de trabajar (Ciselli, 2001). En suma, bajo el auspicio de Mosconi se pusieron en marcha una vasta cantidad de beneficios que, solidificando jerarquías de clase y de género, buscaron fomentar trabajadores y trabajadoras leales a la empresa.

Ahora bien, como se explicitó en el inicio de este trabajo, algunos estudios que se ocuparon de examinar estas medidas interpretaron sus sentidos y alcances acudiendo a distintas categorías. Así, se las vio como un modelo de profundo disciplinamiento social que hizo de YPF una institución total (Cabral Marques, 2011), como parte de una pedagogía de la dominación (Capogrossi; 2014) o como un modelo de hegemonía empresaria (H. Palermo, 2012). Aún cuando responden a marcos teóricos distintos pues la primera se nutre de los postulados del sociólogo canadiense Erving Goffman mientras que las restantes lo hacen de las conceptualizaciones del teórico marxista italiano Antonio Gramsci, estas lecturas coinciden en concluir el éxito de la política de Mosconi a la hora de obtener un obrero obediente a los intereses em-

10. Estudios relativos a la vigencia de estas nociones en otras ramas productivas y comunidades laborales tanto dentro como fuera de la Argentina pueden verse en Klubock (1995), Lobato (2000, 2007), Nari (2004) y S. Palermo (2007).

11. Según algunos trabajos, las coincidencias sobre tipo de valores habrian propiciado los acuerdos entre Mosconi y la congregación salesiana para colocar bajo tutela de esta última la formación de los hijos de los trabajadores en la escuela de artes y oficios comenzada a construir en el campamento en 1929 y concluida en 1937. Véase Carrizo (2009). 
presariales. De tal modo, ese obrero habría pasado a integrarse como engranaje armónico de una singular comunidad laboral en la cual el antagonismo entre capital y trabajo quedaba diluido en la pertenencia a una "gran familia", la de YPF. A su vez, el proceso formativo de esa comunidad y, por tanto, el entramado en que se inscribieron esas medidas fue examinado a la luz de dos nociones fundamentalmente: la de Sistema de Fábrica con Villa Obrera (SFVO) y la de Company Towns.

La primera, formulada por el antropólogo social brasileño José Sergio Leite Lopes $(1979,1988)$, refiere a una comunidad cuyo entramado, dispuesto a partir de una actividad productiva específica y radicada en zonas desprovistas de un mercado de trabajo previo a su creación, concentra en un mismo espacio la esfera de la producción y la de la reproducción de los trabajadores. Tal concentración, que desde el punto de vista de la vida cotidiana tiende a borrar las diferencias entre los momentos de trabajo y los de ocio, da lugar a que la empresa ejerza su poder en todas las esferas de las actividades de los obreros y habitantes de la villa. La pieza clave de esta intromisión está en la provisión de la vivienda y en diversas prácticas de paternalismo empresarial, desplegadas por una institución que es central, el Departamento de Personal. Así, el SFVO gesta un obrero modelado por la empresa, muy distinto al que compone la imagen clásica del "proletario libre" pues tiene una dependencia completa del capital dando lugar a una paradójica servidumbre burguesa (Leite Lopes, 1979, 1988).

Por otro lado, en un libro de Susana Torres y Marcelo Borges (2012), esta definición de SFVO es absorbida por la categoría de Company Towns, una modalidad de asentamiento de la mano de obra rastreable en Europa y Estados Unidos de la revolución industrial. Nuevamente, la clave de su definición se encuentra en la reunión dentro de un mismo espacio geográfico del lugar del trabajo y de vivienda, y la preocupación por atraer mano de obra, fijarla y disciplinarla, lo cual conduce a extender el poder patronal desde el ámbito del trabajo hacia la vida cotidiana fuera de la fábrica, proveyendo servicios y bienes de consumo para los trabajadores, y organizando el uso del tiempo libre.

Las divergencias en el empleo de una y otra categoría en el caso que aquí se trata redundarían más bien en matices. En tal sentido, quienes acuden a la primera parecieran estar más atentos a las grietas que ciertas prácticas obreras abren en el ejercicio de ese poder empresarial, mientras que quienes recurren a la segunda otorgan mayor relevancia a la comprensión del encastre entre las necesidades productivas y el asistencialismo paternalista empresarial fundamentalmente en lo que hace a la voluntad de controlar el tiempo libre. Mas en una y en otra, el protagonismo respecto a la fundación y desarrollo de las comunidades se sitúa en la iniciativa, las prácticas, ideas y concepciones de la patronal. 
Es ese énfasis analítico el que comulga con las evaluaciones sobre el diseño y el resultado de la política asistencial de Mosconi, encerrando distintos problemas para abordar las comunidades como la que examina este trabajo. El mayor de esos inconvenientes radica en la omnipotencia asignada a las patronales empresariales para el ejercicio del control y de la intervención en la cotidianeidad del obrero y su familia, un poder que se presenta como escasamente permeable a fisuras desde abajo a excepción de que las mismas aparezcan como parte de una acción colectiva y organizada. La literatura con la que dialoga este estudio no elude atribuir un papel a los trabajadores en los prolegómenos de la política asistencial pues denota la elevada presencia de anarquistas entre las filas obreras y la intensidad de los conflictos impulsados por la FOP para torcer las severas condiciones laborales y de vida que regian en el yacimiento estatal. Sin embargo, al centrarse exclusivamente en este tipo de acciones colectivas de protesta y formas de organización, la medición del logro de la "domesticación" obrera se asoció a su erradicación. Así, si las huelgas se desactivaron al igual que las organizaciones sindicales, si los trabajadores se radicaban en el lugar, se casaban, llevaban el sustento a su hogar mientras las mujeres velaban por ellos y sus hijos e hijas, si no formaban ningún tipo de asociación autónoma de clase, se capacitaban y jugaban al fútbol, se tornaba evidente que habian aceptado su lugar subordinado dentro de la comunidad, definiendo un sentido compartido de pertenencia que, basado en lo laboral, no era otro que el diseñado por la empresa y Mosconi.

En efecto, las huelgas que poblaron la escena de los campamentos de YPF en 1917, 1918, 1919 y 1920 -si bien hubo dos en 1924 y una en 1927- no volvieron a aparecer siquiera durante el año 1932, cuando dos conflictos iniciados en las compañias privadas se convirtieron en paros generales que convulsionaron a esa región de la Patagonia (Andújar, 2014). Por su parte, los registros sobre deportaciones masivas de anarquistas, la desarticulación de la FOP y la ausencia de una organización sindical que la reemplazara hasta la aparición de la Unión General de Obreros Petroleros, un sindicato de filiación comunista fundado a mediados de 1931, así como la efectiva disminución de la proporción de extranjeros entre los trabajadores, ${ }^{12}$ reforzaron la convicción sobre la desactivación de una clase obrera conciente y organizada en defensa de sus intereses.

Mas estas conclusiones pueden ser revisadas bajo otras considera-

12. Igualmente, Mosconi (1984) exageraba el éxito de su política de argentinización de la mano de obra al señalar que al momento de su renuncia, en 1930, el 80\% de los trabajadores de YPF eran argentinos. Un trabajo basado en el relevamiento de las fichas de personal demuestra que la fuerza laboral nativa para ese entonces representaba el 43,4\%. del total (Castiñeira Castro y García, 1999). 
ciones. La primera requiere sopesar las capacidades de resistencia y organización por fuera de aquellas formas y acciones que son claramente visibles a los ojos del dominador como las huelgas, ya que enfocarse sólo en estas últimas obtura la posibilidad de interpretar otros indicios. En ocasiones, esos indicios aparecen en actitudes individuales contrarias a la disciplina laboral que buscaba imponer la empresa. Así, la revisión de las fichas del personal de YPF comprendidas entre los años 1926 y 1929 hizo posible detectar reproches a los obreros por conductas tales como dormirse en horas de labor, ausentarse sin aviso, asistir al trabajo en estado de ebriedad, realizar lecturas en voz alta en medio de la jornada laboral, lanzar piedras y palas a las cintas del equipo de perforación, contestar de manera insolente al personal jerárquico, desacatar sus órdenes o, como hizo la partera Josefa Ezcurra de Ciafardini, utilizar el automóvil del Hospital Alvear para trasladar a sus amigas a una fiesta. Todos estos comportamientos ameritaban suspensiones que podian durar de uno a cinco días y también pérdida de bonificaciones (lo cual impactaba fuertemente en el salario obrero) cuando no el despido.

Otros indicios son rastreables en los momentos de las huelgas que, aún cuando no comprometieran las instalaciones de YPF, revelaban que no todos sus trabajadores se mantenían al margen. Si se siguen los nombres de los huelguistas apresados por la policía del campamento de YPF en las dos protestas de 1932, por ejemplo, es posible observar que entre los arrojados a las "mazmorras de YPF" (como definía uno de los encarcelados a la comisaría que desde 1916 funcionaba dentro de este campamento), se encontraban algunos obreros de la empresa estatal, sorprendidos en reuniones en las gamelas de los campamentos de la Compañía Ferrocarrilera de Petróleo o de Manantial Rosales (dos de las empresas que fueron epicentro de tales protestas). ${ }^{13}$ Entre los detenidos, además, estaba Alfredo Raffo, integrante de un equipo de fútbol fundado a instancias de la dirección de YPF. ${ }^{14}$ Otros trabajadores figuraban en las listas de los deportados al comienzo de la primera de las dos huelgas de ese año. Por su parte, las crónicas periodísticas que día a día se ocupaban de informar si el conflicto afectaba o no las instalaciones de YPF, al igual que las memorias de Rufino Gómez, un

13. Tal fue el caso de Jacinto Ozán e Ignacio González, dos trabajadores oriundos de Buenos Aires que habían ingresado en YPF a fines de 1928. Ambos fueron deportados con motivo de la primera huelga de 1932 el 19 de marzo de ese año (Libro de partes diarios de la Policía de YPF, parte del 19 de marzo de 1932, tomo 1931-1932, folio 181). Sobre el calificativo dado a las celdas de la comisaria de YPF, véanse las cartas de Jacinto Ozán publicadas en ediciones del diario El Chubut del 4, 5 y 8 de marzo de 1932.

14. Libro de partes diarios de la Policía de YPF, partes del 9 y 10 de marzo, tomo 1931-1932, folios 172 y 173. 
activista comunista llegado a la región patagónica a comienzos del año 1930, referian la presencia de columnas de obreros de esa empresa en las movilizaciones y mitines realizados durante esas protestas. ${ }^{15}$ Más aún, puede presumirse que estas huelgas habrian estimulado a la dirigencia de YPF a satisfacer ciertos reclamos sobre las condiciones de vida y de trabajo, tales como los referidos a las extensas travesías que muchos trabajadores debian recorrer para llegar desde sus moradas dentro del campamento hasta los pozos de perforación. Según explicitaba en agosto de 1932 El Obrero Petrolero, un periódico sindical comunista de Comodoro Rivadavia, entre "las herejías que se cometen" contra los obreros en YPF se encontraba la de tener que levantarse a las 5:30 hs de la mañana para "ir a pie 7, 9 hasta 10 kilómetros a trabajar bajo la lluvia, nieves, vientos y fríos por dentro de las matas". ${ }^{16}$ En apariencia, la dirigencia empresarial habría tomado nota de la denuncia y se determinó que la distancia entre la residencia de los trabajadores y el pozo donde laboraban no podía exceder los $2 \mathrm{~km},{ }^{17}$ disponiéndose en caso contrario "el traslado del personal a nuevos alojamientos". ${ }^{18}$

Igualmente, no es conveniente caer en una sobrevaloración de estos indicios para oponer a las lecturas del omnímodo poder de los patrones una omnimoda capacidad de resistencia de la clase obrera. Pero tomar en cuenta esas prácticas a partir de una perspectiva que se interrogue por la agencia de las trabajadoras y los trabajadores, que no exima el conflicto en la dominación ni desestime las tensiones o reformulaciones permanentes a las que son sometidas desde abajo las instancias de dominación, permite repensar la forma en que fueron edificadas estas comunidades y cómo tal proceso fue parte de la arena de la conflictividad de clases. También colabora en reponer para la reconstrucción de ese pasado cómo los obreros y las obreras desde sus propias experiencias significaron tales políticas y sus alcances. Un ejemplo de ello puede encontrarse en la experiencia de Carmen, la viuda de Julio Montoya. Ciertamente el tipo de trabajo que realizaba para la empresa da cuenta de las jerarquías de género que ésta incentivaba y posibilita suponer que con la atención de los baños públicos ella aceptaba cumplir con lo esperado de su sexo. Pero podemos preguntarnos hasta qué punto esa

15. El Chubut, ediciones de marzo y abril de 1932; Gómez (1973).

16. El Obrero Petrolero, 3 de agosto de 1932, "Carta del Comité Sindical del YPF", p. 3.

17. Expediente $D G n^{\circ} 32$, Ministerio de Agricultura. Administración de los Yacimientos Petroliferos Fiscales. Nota dirigida al Administrador de YPF Ing. Roberto Raventos, 1932, folio A $\mathrm{n}^{\circ}$ 3, Museo del Petróleo, Comodoro Rivadavia.

18. Nota del Ingeniero Roberto Raventos al Jefe de Sondeo y Producción de YPFComodoro Rivadavia, 5 de noviembre de 1932. Folio A 3 5, Museo del Petróleo, Comodoro Rivadavia. 
aceptación no permitía mantener otros márgenes de autonomía pues, de no contar con ese trabajo remunerado, Carmen tal vez se habria visto obligada a retornar con su hijo a Buenos Aires, ese lugar cosmopolita del cual había salido hacía muchos años, buscar y encontrar un trabajo, preocuparse por la educación del niño sin contar con la garantía que le ofrecía YPF con sus escuelas, o resignarse a vivir bajo tutela de un pariente si las cosas se ponían más complicadas. Por tanto, al consentir cuidar y limpiar del baño, ella quizás también sopesó sus posibilidades y resolvió quedarse en el lugar que conocía, donde contaba con relaciones y espacios que servian a sus necesidades y a las formas en que pensaba el mundo en el que le tocó vivir. Otro tanto puede decirse de cuestiones como el proceso de argentinización y la identificación obrera con las banderas del nacionalismo petrolero que redundaban en la existencia de esa comunidad. No es del todo claro aún cómo vivieron los catamarqueños que fueron contratados por YPF, cómo se relacionaron con los restantes obreros, de qué manera tejieron solidaridades y conflictos con españoles, portugueses o alemanes, cuáles eran sus nociones de familia, sus esperanzas, sus visiones politicas de la realidad circundante. Menos aún se conoce qué componentes tuvo la idea de nacionalismo para ellos, para los restantes trabajadores y trabajadoras o, incluso, cuántas definiciones de nacionalismo petrolero circulaban entre ellos.

\section{A modo de cierre}

Aquello que sí se sabe, como ya lo marcó E.P. Thompson (1989), es que la batalla final por la disciplina industrial la ganó el capital. Y podría decirse, parafraseándolo, que la batalla final por el sentido de comunidad la ganó YPF si se tiene en cuenta que varios años más tarde los obreros petroleros comenzaron a autoidentificarse como ypefeanos, subsumiendo otras pertenencias a las correspondientes a su papel en la comunidad laboral. Pero como también señala el historiador británico, ello no exige invalidar la entidad de las "escaramuzas" que se libraron en medio de esa batalla para quedarse tan solo con lo que arroja el final del camino. No obsta preguntar cuánto tejian los obreros de carne y hueso su participación política cuando se juntaban a jugar al fútbol, qué visiones y emprendimientos compartían cuando asistian a las veladas musicales organizadas por YPF, cuánto intervinieron en su propia disciplina y códigos de conducta las prédicas de los anarquistas contra la ebriedad, por ejemplo, o qué estarian leyendo en voz alta a sus compañeros en horas de trabajo. Es más, hasta podría pensarse cómo interpretar incluso la dificultad de encontrar mayor cantidad de rastros de ese tipo: ¿obra de escasa existencia o importante capacidad de ocultamiento de las prácticas obreras a los registros del patrón? James 
Scott (2000) ha proporcionado un iluminador análisis para atisbar esa infrapolitica de los oprimidos, esas estratagemas de veladas y discretas oposiciones tendientes a limitar el poder de los dominadores, puestas en escena cuando un "ataque frontal" es percibido como imposible. Por su parte, Florencia Mallon (2003) ha propuesto hace tiempo repensar la hegemonía no sólo como un resultado sino como un proceso en el cual se legitiman, redefinen y disputan poderes y significados identitarios en todos los niveles de la sociedad. Perder de vista ese proceso conlleva el riesgo de cegarse a las demandas y los términos de los trabajadores y las trabajadoras porque estos quedan sumergidos y reorganizados en otros modos al momento del resultado. En tal sentido, el respeto a su dignidad como obrero, a ganar un salario que permitiera reproducir el hogar proletario, a contar con vivienda y cobertura de salud, a determinar su tiempo de trabajo y su tiempo libre, a exigir el acortamiento de distancias entre la morada y el pozo petrolero, constituyeron demandas por derechos edificadas en base a la manera en que esos trabajadores y trabajadoras experimentaron sus condiciones de explotación. De tal modo, esas reivindicaciones configuraron y se reconfiguraron desde una práctica política y social que enmarcó el terreno de la lucha de clases "desde abajo", aún cuando en sus resultados predomine fundamentalmente la firma de Mosconi y la afirmación de su complacencia por haber logrado formar a ese "personal de hombres fuertes, sanos de cuerpo y espíritu".

Este trabajo buscó resituar ese proceso, interrogándose por las experiencias de trabajadores y trabajadoras, a fin de hallar la pátina de sus estrategias abiertas y solapadas, individuales y colectivas, y de sus expectativas y percepciones en la formulación de los beneficios de que fueron objeto bajo la dirigencia de Mosconi. También procuró reflexionar sobre la formación de esa comunidad laboral examinándola no como la resultante obvia de las necesidades del capital y las voluntades patronales, sino como el fruto de una construcción activa, relacional e histórica -y por tanto conflictiva-, una edificación a ser examinada no por la apariencia de su puerto de llegada sino a la luz de lo que hicieron, idearon y comprendieron todos los sujetos que formaron parte de ella.

\section{Bibliografia de referencia}

Andújar, Andrea (2014), "En demanda de lo justo: conflictos por derechos en la Patagonia petrolera. Comodoro Rivadavia, 1932", Páginas. Revista Digital de la Escuela de Historia, año 6, $\mathrm{n}^{\circ}$ 12, Universidad Nacional de Rosario. Disponible en línea.

Armesto, Stella, Elvira Córdoba y Raúl Figueroa (2001), Comodoro Rivadavia, crónicas del centenario, 1901-2001, Comodoro Rivadavia: Diario Crónica. 
Cabral Marques, Daniel (2010), "La constitución de una "gran familia": trabajadores e identidades sociolaborales en las empresas extractivas estatales de la Patagonia Austral", en $1^{\circ}$ Workshop sobre conflictividad y consentimiento en las relaciones laborales. Prácticas obreras y empresarias en la Argentina del siglo XX, Tandil.

- (2011), "La expansión de los yacimientos estatales en la Patagonia austral y la consolidación de un modelo de regulación sociolaboral bajo la égida de YPF: 1930-1946", en Enrique Mases (comp.), Trabajadores y trabajadoras en la Argentina. Aportes para una historia social, Neuquén: Universidad Nacional del Comahue.

- (2013), "Mundos del trabajo y formas de organización sindical en la Cuenca del Golfo de San Jorge durante la primera mitad del siglo XX: entre la radicalización obrera, el planteo reivindicativo y la articulación con el Estado", en Avances del Cesor, año X, no 10, Rosario: ISHIR-Conicet-UNR.

Cabral Marques, Daniel y Edda Lía Crespo (2006), "Entre el petróleo y el carbón: empresas estatales, trabajadores e identidades sociolaborales en la Patagonia austral durante el período territoriano (1907-1955)", en Susana Bandieri, Graciela Blanco y Gladis Varela (dirs.), Hecho en Patagonia. La historia en perspectiva regional, Neuquén: CEHIR-EDUCO, Universidad Nacional del Comahue.

Capogrossi, Lorena (2014), "Disciplinamiento y nacionalización de la fuerza de trabajo en los campamentos petroleros argentinos", en Nuevo Mundo Mundos Nuevos (en línea).

Castiñeira Castro, Víctor Manuel y Alfredo Martín García (1999), "Aproximación a la emigración española a la provincia del Chubut: los yacimientos petroliferos fiscales (1915-1933)", en Anuario de Estudios Americanos, vol. $56, \mathrm{n}^{\circ} 2$.

Carrizo, Gabriel (2006), "Los trabajadores y su tiempo libre. El fútbol en las comunidades obreras de Comodoro Rivadavia durante las primeras décadas del siglo XX", Segundas Jornadas de Historia de la Patagonia Universidad Nacional del Comahue, 2, 3 y 4 de noviembre.

- (2009), "Educación y masculinidad en un colegio técnico de la Patagonia argentina: el caso de los salesianos en Comodoro Rivadavia durante la primera mitad del siglo XX", Revista de Investigación Educativa, $\mathrm{n}^{\circ} 9$, julio-diciembre, Xalapa: Universidad Veracruzana.

Ciselli, Graciela (2001), "La mujer italiana en la industria petrolera del sur Patagónico", Gazeta de Antropología, n ${ }^{\circ} 21$.

- (2002), "Trabajo femenino en la industria petrolera de Chubut (19191962)", Andes, ${ }^{\circ}$ 13. En http: redalyc.unamex.mx.

Crespo, Edda Lía (2001), "De Germinal a Florentino Ameghino. Memoria, política y asociacionismo en Comodoro Rivadavia (1919-1923)", Entrepasados, año $\mathrm{X}, \mathrm{n}^{\circ} 20-21$.

- (2005), "Madres, esposas, reinas... Petróleo, mujeres y nacionalismo en Comodoro Rivadavia durante los años del primer peronismo", en Mirta 
Lobato (ed.), Cuando las mujeres reinaban. Belleza, virtud y poder en la Argentina del siglo XX, Buenos Aires: Biblos.

Ezpeleta, Justo (dir.) (1957), Medio siglo de petróleo argentino. 1907-13 de diciembre-1957, Comodoro Rivadavia: El Rivadavia.

Gadano, Nicolás (2006), Historia del petróleo en Argentina, 1907-1955: desde los inicios hasta la caida de Perón, Buenos Aires: Edhasa.

Gómez, Rufino (1973), La gran huelga petrolera en Comodoro Rivadavia (1931-32). En el recuerdo de un militante obrero y comunista, Buenos Aires: Ediciones Centro de Estudios.

Klubock, Thomas (1995), "Hombres y mujeres en El Teniente: la construcción de género y clase en la minería chilena del cobre, 1904-1951", en Lorena Godoy (ed.), Disciplina y desacato: construcción de identidad en Chile. Siglos XIX y XX, Santiago de Chile: CEDEM.

Leite Lopes, José Sergio (1979), "Fabrica e Vila Operaria. Considerações sobre uma forma de servidão burguesa", Mudança social no Nordeste, Río de Janeiro: Paz e Terra.

- (1988), A Tecelagem dos conflitos de classe na cidade das chaminés, São Paulo: MCT/CNPq.

Lobato, Mirta Z. (2000), "Lenguaje laboral y de género en el trabajo industrial”, en F. Gil Lozano, V. Pita y M.G. Ini (dirs.), Historia de las mujeres en la Argentina. Siglo XX, tomo 2, Buenos Aires: Taurus.

- (2007), Historia de las trabajadoras en la Argentina (1869-1960), Buenos Aires: Edhasa.

Mallon, Florencia (2003), Campesino y nación: la construcción de México y Perú postcoloniales, México: Historias.

Márquez, Daniel (1995), "Conflicto e intervención estatal en los orígenes de la actividad petrolera en Comodoro Rivadavia”, en Daniel Márquez y Mario Palma Godoy, Distinguir y comprender. Aportes para pensar la sociedad y la cultura en Patagonia, Comodoro Rivadavia: Proyección Patagónica.

Mosconi, Enrique (1984), Obras, Buenos Aires: YPF.

Nari, Marcela (2004), Politicas de maternidad y maternalismo politico, Buenos Aires: Biblos.

Palermo, Hernán (2012), Cadenas de oro negro en el esplendor y ocaso de $Y P F$, Buenos Aires: Antropofagia.

- (2014), "Machos que se la bancan: masculinidad y disciplina fabril en la industria petrolera argentina", Desacatos. Revista de Antropología Social, $\mathrm{n}^{\circ} 47$, enero-abril. Disponible en línea.

Palermo, Silvana (2007), “¿Trabajo masculino y protesta femenina? La participación de las mujeres en la gran huelga ferroviaria de 1917", en M.C. Bravo, F. Gil Lozano y V. Pita (comps.), Historia de luchas, resistencias y representaciones. Mujeres en la Argentina, siglos XIX y XX, Tucumán: EDUNT.

Scott, James (2000), Los dominados y el arte de la resistencia, México: Era. Solberg, Carl (1986), Petróleo y nacionalismo en la Argentina, Buenos Aires: Hyspamérica. 
Thompson, E.P. (1989), La formación de la clase obrera en Inglaterra, Barcelona: Critica.

Torres, Susana (1995), "Huelgas petroleras en Patagonia: inmigrantes europeos, clase y etnicidad (1917-1933)", en V Jornadas sobre Colectividades, IDES, Buenos Aires, 26 y 27 de octubre.

Torres, Susana y Marcelo Borges (2012), Company Towns: Labor, space and power relations across time and continents, Nueva York: Palgrave Macmillan.

$$
* * *
$$

Título: Working-class community, gender and welfare policies: a historical approach, Comodoro Rivadavia, 1922-1932

Resumen: Este artículo explora el problema histórico de las comunidades obreras y las politicas asistenciales desplegadas por el empresariado a favor de los trabajadores y sus familias a partir de un caso específico: Yacimientos Petrolíferos Fiscales (YPF) en Comodoro Rivadavia entre 1922 y 1932. Inscripto en la historia social con perspectiva de género, se interroga por la politica asistencial de la empresa y por la manera en que los trabajadores petroleros gravitaron en la edificación de esa comunidad.

Palabras clave: comunidad obrera - género - política asistencial - Comodoro Rivadavia.

Abstract: This article explores the historical problem of working-class communities and the welfare policies undertaken by employers towards workers and their families in a specific case: the Yacimientos Petroliferos Fiscales (YPF) in Comodoro Rivadavia between 1922 and 1932. It combines a social history approach with a gender perspective in order to examine the welfare policy in the company and how petroleum workers affected the building of that community. Keywords: working-class community - gender - welfare policy - Comodoro Rivadavia.

Recepción: 10 de junio de 2015. Aprobación: 11 de julio de 2015 